\title{
High Efficiency Germanium Immersion Gratings
}

P. J. Kuzmenko, P. J. Davis, S. L. Little, L. M. Little, J. V. Bixler

May 5, 2006

Opto-Mechanical Technologies for Astronomy Orlando, FL, United States

May 24, 2006 through May 31, 2006 
This document was prepared as an account of work sponsored by an agency of the United States Government. Neither the United States Government nor the University of California nor any of their employees, makes any warranty, express or implied, or assumes any legal liability or responsibility for the accuracy, completeness, or usefulness of any information, apparatus, product, or process disclosed, or represents that its use would not infringe privately owned rights. Reference herein to any specific commercial product, process, or service by trade name, trademark, manufacturer, or otherwise, does not necessarily constitute or imply its endorsement, recommendation, or favoring by the United States Government or the University of California. The views and opinions of authors expressed herein do not necessarily state or reflect those of the United States Government or the University of California, and shall not be used for advertising or product endorsement purposes. 


\title{
High Efficiency Germanium Immersion Gratings
}

\author{
Paul J. Kuzmenko*, Pete J. Davis, Steve L. Little, Liesl M. Little, and Jay V. Bixler \\ Lawrence Livermore National Laboratory, L-183 PO Box 808, Livermore, CA 94551
}

\begin{abstract}
We have fabricated several germanium immersion gratings by single crystal, single point diamond flycutting on an ultraprecision lathe. Use of a dead sharp tool produces groove corners less than 0.1 micron in radius and consequently high diffraction efficiency. We measured first order efficiencies in immersion of over $80 \%$ at 10.6 micron wavelength. Wavefront error was low averaging 0.06 wave rms (at $633 \mathrm{~nm}$ ) across the full aperture. The grating spectral response was free of ghosts down to our detection limit of 1 part in $10^{4}$. Scatter should be low based upon the surface roughness. Measurement of the spectral line profile of a $\mathrm{CO}_{2}$ laser sets an upper bound on total integrated scatter of $0.5 \%$.
\end{abstract}

Keywords: immersion grating, germanium, diffraction efficiency, diamond machining

\section{INTRODUCTION}

Spectral analysis is the source of nearly all the information we have on the composition of astronomical objects. There are important terrestrial applications as well. These include remote sensing of air pollutants as well as the monitoring of gases implicated in ozone depletion and climate change. Diffraction gratings are key components of most modern spectrometers.

It was realized over 50 years ago that there were benefits to fabricating diffraction gratings on optically transmissive materials and using them in immersion mode ${ }^{1}$. By this we mean that the incident electromagnetic waves approach the grating through a transmissive medium not through the air (see figure 1). The diffractive structure is therefore "immersed" in a material with a refractive index greater than one.

The spectral resolution of a diffraction grating is proportional to the grating length in wavelengths. In immersion the effective wavelength is $\lambda_{0} / n\left(\lambda_{o}\right)$ where $\lambda_{o}$ is the free space wavelength and $n$ is the refractive index. So one of the effects of immersing an echelle grating is to magnify its spectral resolution by the factor $\mathrm{n}$. Immersion also increases the grating dispersion by the factor $\mathrm{n}$. These effects can be dramatic for infrared transmitting materials like germanium ( $\mathrm{n} 4$ ). Replacing the conventional reflective echelle grating in a spectrometer with an immersion grating can quadruple the spectral resolution of the instrument. Alternately, one can greatly reduce the size of a spectrometer, which normally degrades its resolution, and then restore the resolution to its original value by installing an immersion grating. This can have a profound effect on the design of airborne and spaceborne systems with critical size and weight limits. Terrestrial systems with large vacuum dewars and cryogenic systems can benefit from cost reductions due to the reduced size of the optical package. For first order gratings used in imaging spectrometers, immersion reduces the angles of incidence and diffraction at the grating surface, which reduces slit curvature and other aberrations at the focal plane.

Conventional reflection gratings are ruled with diamond tools in soft ductile metal films. Unfortunately most optically transmissive materials are brittle. Attempts to rule brittle materials result in chipped, fractured surfaces. Over the past 10 to 15 years advanced fabrication techniques have been applied with some success, most notably the use of anisotropic chemical etching to produce gratings in silicon ${ }^{2,3,4,5}$. Physical fabrication techniques such as reactive ion etching ${ }^{6}$, ion milling $^{7}$ and diamond machining ${ }^{8}$ have also achieved success and are applicable to a wider variety of materials.

At LLNL efforts have focussed on single crystal, single point diamond flycutting of germanium immersion gratings for long wave infrared ( 8 to $13 \mu \mathrm{m}$ ) applications. We recently demonstrated $80 \%$ diffraction efficiencies in first order at $10.6 \mu \mathrm{m}$ wavelength, which was very close to theoretical predictions. Section 2 will review prior work at LLNL and

*Author information: Email: kuzmenko1@1ln1.gov; Telephone: (925) 423-4346; Fax: (925) 422-2499 
elsewhere on germanium immersion gratings. In section 3 we will discuss the efficiency measurements on the early LLNL gratings. Section 4 will cover the efficiency measurements on later LLNL gratings. A discussion of the results followed by conclusions is in section 5 .

\section{REVIEW OF PRIOR WORK ON GERMANIUM GRATINGS}

Silicon immersion gratings have attracted the most development effort due in part to the large technology base originating in the microelectronics industry. However for work outside of the transmission range of silicon other materials must be considered. In the long wave infrared atmospheric window (nominally from 8 to $13 \mu \mathrm{m}$ ) germanium is the material of choice. It has the highest refractive index of common materials and possesses good transmission from 2 to $14 \mu \mathrm{m}$. Optical quality germanium is readily available in large sizes, up to 10 inch diameter from Umicore and up to $400 \mathrm{~mm}$ diameter from TDY Co. of Japan.

The first attempts at fabricating gratings in germanium were based on chemical etching techniques similar to those successfully employed in silicon. Unfortunately the etch anisotropy achieved in germanium was very low (only 2 or 3 vs. 100 for silicon) and no usable gratings resulted ${ }^{9}$.

\subsection{Work at RIKEN (Japan) on nanoprecision grinding}

Workers at RIKEN (The Institute of Physical and Chemical Research) in Japan have an ongoing program to produce a large, coarse echelle ( $120 \times 120 \mathrm{~mm}$ entrance aperture, $68.75^{\circ}$ blaze, $600 \mu \mathrm{m}$ groove spacing $)$ in germanium for the MidInfrared High Dispersion Spectrograph for the SUBARU Telescope. They originally tried oblique ion etching and ablation with an excimer laser to cut grooves. Neither technique gave good quality in the deep grooves required for the echelle ${ }^{7}$. Success was achieved in fabricating $1 / 4$ scale prototype gratings $\left(30 \times 30 \mathrm{~mm}\right.$ entrance aperture, $68.75^{\circ}$ blaze $)$ on a nanoprecision $3 \mathrm{D}$ profile grinding machine. Several passes with a \#4000 diamond wheel for rough grinding were followed with a finishing pass with a \#20000 diamond wheel. Special care was taken to periodically true and refinish the diamond wheels in order to maintain sharp grooves. The groove corner radius increased due to tool wear during the grinding process from $15 \mu \mathrm{m}$ at the first groove to $28 \mu \mathrm{m}$ on the last $\left(472^{\mathrm{nd}}\right)$ groove. Their best grating had an $\mathrm{rms}$ surface roughness of $3.0 \mathrm{~nm}$ and a wavefront error of about $600 \mathrm{~nm}$ peak to valley and $100 \mathrm{~nm} \mathrm{rms}{ }^{10}$. No diffraction efficiencies were measured and there was evidence of periodic error and thermal drift in groove position. Still these are impressive results.

\subsection{Work at LLNL on ultraprecision diamond flycutting}

At LLNL development of a germanium immersion grating to support a long wave infrared spectrometer design was proposed in 1999. We believed that diamond machining offered the best hopes of successful fabrication. One year later inquiries went out to diamond machining shops requesting bids but with little positive response. At that point we turned to in-house capabilities and expertise which were excellent. LLNL has been on the leading edge of diamond machining research since the late 1970's and has several world class machines.

The optical design ${ }^{11}$ for what became known as the DS/1 spectrometer (see figure 2) was finalized in 2002. It called for a grating with grooves cut on the hypotenuse of a right angle prism and relied on total internal reflection at the groove surface. This meant separate entrance and exit faces. The DS/ 1 gratings were designed to have a $21.4 \mu \mathrm{m}$ line spacing, a $5.3^{\circ}$ blaze angle and a ruled area of roughly $11 \mathrm{~mm} \times 14 \mathrm{~mm}$.

Details of the fabrication procedure were given in a previous paper $^{12}$, but will be summarized here. We start with a blank of single crystal germanium, rough ground to shape so that none of the grating surfaces will be closely aligned with the (111) cleavage planes of the material. Next the blank is chemically etched to remove the outermost layers containing subsurface damage from the grinding process. The blank is then fixtured onto the X-translation stage of an ultraprecision lathe (the PERL-II) and is ready to be machined. The machine configuration is set up for flycutting as shown in figure 3. The spindle holds a single crystal diamond tool whose tip is shaped to match the desired groove profile. As the spindle rotates the stage slowly translates so that a small bit of germanium is sliced off on each revolution. After completing a groove, the spindle retracts and the translation stage moves back to its starting position. The spindle moves forward into position to cut the next groove and the process is repeated. 
We verified the machining process by first cutting a grating in a small block of OFHC copper. Optical testing showed that it was of good quality. The next attempt was with a germanium blank and was also successful.

Preliminary test results on the DS/1 germanium immersion grating were presented at the SPIE meeting on Astronomical Telescopes and Instrumentation in Kona Hawaii in $2002^{12}$. We measured the groove roughness with an atomic force microscope ( $1.1 \mathrm{~nm}$ rms over a $5 \mu \mathrm{m} \times 5 \mu \mathrm{m}$ area) and the wavefront aberration with a Zygo interferometer ( 0.05 wave peak to valley and 0.010 wave rms at $633 \mathrm{~nm}$ over a $6 \mathrm{~mm}$ x $6 \mathrm{~mm}$ aperture). The diffraction pattern from a visible HeNe laser was clean with very little scatter. Since the entrance and exit facets had not yet been antireflection coated, we were unable to measure diffraction efficiency.

\section{MEASUREMENTS ON DS/1 GRATINGS}

Grating \#1 was later recut when it was noticed that the grooves near one edge had not been cut to their full depth. Two more gratings were cut shortly thereafter and also measured for wavefront error. Grating \# 2 was 0.28 wave p-v and 0.049 wave rms over the full $11 \mathrm{~mm} \times 14 \mathrm{~mm}$ aperture. Grating \# 3 was 0.22 wave p-v, 0.033 wave rms over the full aperture and 0.046 wave p-v, 0.009 wave rms stopped down to $7 \mathrm{~mm}$ diameter aperture. These measurements were made with the germanium blanks still fastened to the fixture block in which they were cut. Grating \#2 was retested 6 months later, now released from the fixture and with antireflection coatings on the entrance and exit faces. The rms wavefront error had increased by a factor of 5 due to the surface taking on a slight cylindrical shape. The cause remains a matter for further study. A third test 18 months after the second one showed no further changes.

Diffraction efficiency varies with wavelength. An efficiency measurement requires a monochrometer, a broadband source and a detector with a calibrated or flat spectral response. One can also test the grating as part of a complete spectrometer. However, one needs to know the spectral transmission of each optical element as well as the spectral response of the detector in order to isolate the performance of the grating. A third option, one that would still yield much useful information, is to measure diffraction efficiency at a single wavelength by use of a laser. We chose this option.

Rocky Mountain Instrument deposited a broadband ( 8 to $13 \mu \mathrm{m}$ ) antireflection coating on both the entrance and exit surfaces of all 3 gratings. We measured a normal incidence reflectivity of $1.7 \%$ at $10.6 \mu \mathrm{m}$.

The DS/1 gratings were tested with a low power, air-cooled CO2 laser (TS Team model 10WA). It was a waveguide laser with good $\mathrm{TEM}_{00}$ modes and random polarization. A beam of about 3 watts intensity was directed onto the entrance face. Through the use of fluorescent cards we were able to locate the diffracted beams from 3 grating orders and measure them with a thermopile power meter. Only about $40-45 \%$ of incident power was diffracted into the desired $1^{\text {st }}$ order, with about $30-35 \%$ in the zero order and $1 \%$ in the $2^{\text {nd }}$ order. All three gratings gave very similar results.

An examination of the grating equation showed 16 allowed diffraction orders at $10.6 \mu \mathrm{m}$. However, a trace of the ray paths reveals that all but the 3 observed orders undergo total internal reflection as they try to exit the prism. The total power in these orders, which is calculated to be small, is either absorbed or leaks out in many different directions.

The distribution of energy among allowed diffraction orders is primarily a function of groove shape. Atomic force microscope (AFM) images showed that except in the corners the groove surfaces were smooth and planar. So the next thing to check was the blaze angle. This was done with a HeNe laser. We first identified the zero order reflection then measured the angles and relative intensities of the two brightest diffraction orders. By interpolating between the positions of the brightest orders weighted by their intensities ${ }^{13}$ the blaze angle was determined to be $3.7^{\circ}$. This was only $70 \%$ of the specified value.

It makes physical sense that a smaller blaze angle will shift the peak of efficiency to shorter wavelength. There was some indication of this in the spectrometer performance. Rerunning the Gsolver code also showed that the zero order energy at $10.6 \mu \mathrm{m}$ would increase as observed with the $\mathrm{CO}_{2}$ laser. Optical inspection of diamond tool showed that blaze angle was in error because the tool tip was not cut at proper angle. The actual tool angle was consistent with measured blaze. We worked with tool vendor on inspection techniques so that the angles on subsequent tools were within $0.1^{\circ}$ of specification. 


\section{DESIGN AND FABRICATION OF DS/2 GRATINGS}

In 2004 a new compact spectrometer design ${ }^{15}$ called DS/2 (see figure 4) was developed at LLNL requiring a somewhat different style immersion grating. This new grating has a more conventional configuration. Light enters the front surface of a slightly wedged prism, reflects off the back grating surface and exits through the front surface. Since the angle of incidence on the grating facets is below the critical angle the grooves need a high reflectivity coating (see Appendix 1). An aspheric shape is diamond machined into the front surface to correct for aberrations.

A preliminary optical design gave the following grating parameters: period of $16.7 \mu \mathrm{m}$, ruled area of 9.65 by $12.14 \mathrm{~mm}$, and prism wedge angle of $2.12^{\circ}$. Diffraction efficiency was modeled with GSolver to determine the optimal blaze angle and to verify the groove shape. Results are shown in figure 5. The optimum blaze angle for coverage from 8 to $13 \mu \mathrm{m}$ is $4.15^{\circ}$. One surprise was the need to cut very sharp groove corners. A typical diamond tool has a tip radius of a few microns, and this radius is replicated in the groove corner. Modeling done for the DS/ 1 grating showed that a $3 \mu \mathrm{m}$ radius was adequate to achieve maximum diffraction efficiency. For the DS/2 grating reducing the corner radius from 3 $\mu \mathrm{m}$ to $0.5 \mu \mathrm{m}$ improved the diffraction efficiency by about $13 \%$. Our goal was to achieve a radius of less than $0.5 \mu \mathrm{m}$. A final optimization of the optical design gave revised grating specifications of $18.63 \mu \mathrm{m}$ period and a $3.73^{\circ}$ blaze angle (see figure 6).

Two existing diamond tools were sent out for regrinding. They would be cut for the new blaze angle with the tip as sharp as possible (dead sharp). After receiving the reground tools we attempted to cut a grating in a germanium blank. The results were very disappointing as can be seen in figure 7. The vertical groove faces were chipped off and appeared totally destroyed. We originally speculated that the back edge of the tool had dragged across the surface after making the cut causing the damage. The tools were sent back for rework. But after rework the results were the same.

There were two small causes for optimism. The horizontal faces, which are the active surfaces in the grating, are quite smooth. There is some hint of a sharp groove radius at the edge of the grating where the cutting begins. An SEM photo taken with an edge on view confirms this. Figure 8 shows a groove radius of $<0.1 \mu \mathrm{m}$. Although the vertical face is broken off less than a micron above the corner, the radius looked good. We needed to figure out a way to keep from fracturing the vertical faces. Meanwhile, two gratings (\#1 and \#2) were cut using an existing diamond tool ( $3 \mu \mathrm{m}$ radius, $3.7^{\circ}$ blaze) in order that spectrometer development could proceed.

After some experimentation it was found that slowing the feed rate from $0.5 \mathrm{inch} /$ minute down to $0.1 \mathrm{inch} / \mathrm{minute}$ eliminated fracture of the vertical faces. This is the speed at which the grating blank is translated horizontally under the rotating tool bit and the speed at which the groove is cut. Figure 9 shows the high quality and sharp corners of germanium gratings fabricated by this procedure. Figure 10 shows the corner radius of $<0.1 \mu \mathrm{m}$.

\section{TEST RESULTS WITH DS/2 GRATINGS}

A total of four gratings (\#3, \#4, \#5, and \#6) were cut using the dead sharp diamond tools and the reduced feed rate. A photo of a finished grating is shown in figure 11. The cutting time approached 85 hours but we believe that with some modifications in tool design it can be greatly reduced. Nevertheless the environmental stability of the machine room was excellent and there is no sign of diurnal variations across the gratings.

\subsection{Interferometric tests of wavefront error}

Several of the gratings were tested on a Zygo interferometer at $633 \mathrm{~nm}$ for wavefront error. Gratings \#1 and \#2 fabricated with the old style tool had full aperture rms errors of 0.120 and 0.079 waves respectively. When power is removed and the aperture stopped down to $7 \mathrm{~mm} \times 7 \mathrm{~mm}$ the rms errors drop to 0.044 and 0.036 wave. Gratings \#4, \#5 and \#6 fabricated with the dead sharp tool at a reduced feedrate had full aperture rms errors (power removed) of 0.052 , 0.078 and 0.058 waves respectively. Stopping the aperture down to $7 \mathrm{~mm}$ by $7 \mathrm{~mm}$ further reduced the rms errors to $0.042,0.051$, and 0.052 waves. All these measurements are made on uncoated gratings. A oblique plot of the grating \#4 topography is given in figure 12 . 


\subsection{Blaze angle measurements}

Measurements using a $633 \mathrm{~nm}$ HeNe laser of the relative diffraction efficiency for gratings \#2 (3 $\mu \mathrm{m}$ radius) and \#3 (0.1 $\mu \mathrm{m}$ radius) are shown in Figure 13. The gratings were illuminated at near normal incidence using the laser and the intensity of the diffracted peaks recorded with an optical power meter. Grating \#2 (blue triangles) was one of the first gratings ruled and had a non-flat groove profile which results in the distribution of significant energy across several orders. Grating \#3 (red pluses) has nearly perfect triangular groove profiles and the tightening of the diffracted power distribution is easily seen. Also plotted is the sinc ${ }^{2}$ energy distribution function expected for $632.8 \mathrm{~nm}$ light illuminating triangular grooves at near normal incidence to the facets. The best fitting location of the $\operatorname{sinc}^{2}$ peak is for a blaze angle of $3.74^{\circ}$, which is right on the design specification.

\subsection{Diffraction efficiency measurements}

The gratings must be coated before measuring diffraction efficiency. Before coating each grating was solvent cleaned along with a 1 inch diameter germanium wafer to be used as a witness tab. No stronger processes (i.e. RCA clean) were used as we did not want to increase surface roughness. Next they were loaded in the sputtering chamber, which had recently had its deposition rates calibrated. An adhesion layer of $5 \mathrm{~nm}$ of chromium was deposited followed by $150 \mathrm{~nm}$ of gold onto the grating surface. Finally they were sent to Rocky Mountain Instrument where a broadband antireflection coating as deposited on the entrance face.

The measurement is straightforward. Direct a CO2 laser onto the grating and take the ratio of the power in the desired diffracted order to the total incident power. Because the metallic coating on the grooved surface has some infrared absorption, it is important to perform the measurement with as little laser power as possible to avoid thermal effects. We used the same $\mathrm{CO}_{2}$ waveguide laser as was used to test the DS/1 gratings. Its output can be reduced to about one watt, but it is not very stable under that condition. Instead we used a coated piece of zinc selenide as a beam splitter to reflect about $20 \%$ of the beam, while operating the laser at about 1.4 watts. The splitter was tilted at only $5^{\circ}$ from the beam normal to avoid polarization effects. A power meter was placed in the transmitted beam to monitor and correct for drifts in laser power.

Gratings were mounted so that the beam from the splitter was incident at the proper angle. The first order diffracted beam was directed toward a second power meter. Both meters were calibrated to read the same values of power at the start of the experiment. The laser operated in a good $\mathrm{TEM}_{00}$ mode. The grating was positioned about one Rayleigh range from the laser output, which gave a beam diameter $\left(3 \mathrm{w}_{0}\right)$ of about $7 \mathrm{~mm}$ at the entrance face.

The first tests were with the witness tab. The reflectivity from the gold surface was measured to be just over $97 \%$, which is within a percent of the generally accepted value. However when the witness tab was turned around and the gold coating used in immersion, only $85 \%$ reflection was observed. The theory of normal incidence Fresnel reflection, using optical constants for $\mathrm{Cr}$ and $\mathrm{Au}$ from Palik ${ }^{16}$, would suggest a value closer to $93 \%$. Perhaps there was absorption and heating in the germanium. Also the germanium in the wafer is not the same material as that in the grating blanks.

Gratings \# 1 and \# 2 were tested first and measured only about 50\% and $60 \%$ respectively. Both of these were cut with the old rounded tool. In addition, the reflective coatings had been sputtered before the deposition process had been calibrated. It is believed that $20 \mathrm{~nm}$ of chromium had been deposited beneath the gold which is 4 times thicker than desired.

Two of the gratings (\#3 and \#4) cut with the dead sharp tool were tested. These performed well with efficiencies of $82 \%$ and $81 \%$ (average of 2 measurements). These values are consistent with later measurements of spectrometer throughput. They compare very favorably with the predictions of GSolver shown in figure 6 . The code predicts about $84 \%$ efficiency for unpolarized $10.6 \mu \mathrm{m}$ radiation. 


\subsection{Measurements of spectral line profile for evidence of ghosts and scatter}

Measurements of the spectral line profile obtained with the full up spectrometer are shown in Figure 14. The central line profile is in excellent agreement with modeled expectations. There is no hint of ghosting in the wings. Using the rms value of the line wing count levels, an upper limit of $1 \mathrm{e}-4$ can be set on ghosting.

The expected total integrated scattering level can be estimated from the standard approximation:

$$
T I S=\left(4 \pi \sigma n \cos \theta_{i} / \lambda\right)^{2}
$$

Where $\sigma, n, \theta_{i}$, and $\lambda$ are the rms surface roughness, grating substrate index of refraction, incidence angle and wavelength respectively. For $\sigma=1.1 \mathrm{~nm}$ rms roughness, $\lambda=10.6 \mu \mathrm{m}, \mathrm{n}=3.9$, and near normal incidence the total integrated scattering is expected to be $\sim 3$.e-5. Assuming that this scattered light is spread out only over the limited angular range of our spectrometer's 258 spectral bins, the scattered light per spectral bin would be $\sim 1$.e-7 of the line peak. Given the 16000 count range of our spectrometer's digitizer the maximum scattering signal we should observe is a $\sim 0.002$ count increase of the laser-on versus the laser-off measurement. This level of precision is not realistically acheivable for our laboratory set-up. The slightest shift in thermal state between the laser-on and laser-off measurements will result in systematic errors that can easily overwhelm the scattering level.

It is still useful to calculate upper limits to the scattering. As can be seen from Figure 14b, when the background measurement is subtracted from the laser-on data the resulting count levels are near zero over most of the detector. Integrating the line wing count level and dividing by the line peak yields an upper limit of $0.5 \%$ scattering.

\section{DISCUSSION AND CONCLUSIONS}

We have fabricated several small germanium immersion gratings of high optical quality and of high diffraction efficiency for first order operation in the 8 to $13 \mu \mathrm{m}$ band. The combination of $>80 \%$ peak efficiency, $0.06 \lambda$ rms full aperture wavefront error at $633 \mathrm{~nm}$ (equivalent to $0.015 \lambda \mathrm{rms}$ in immersion at $10 \mu \mathrm{m}$ ), ghosting of less than $10^{-4}$ and low scatter makes a very compelling case for applications in the long wave infrared.

One may ask if comparable performance can be achieved with alternative technologies, for example etched silicon. Because its refractive index is slightly lower a silicon grating of comparable performance would need to be $18 \%$ thicker with a higher blaze angle. The DS/2 gratings are fairly thin, about 0.095 inch at the center. This gives an optical path of about $0.5 \mathrm{~cm}$ in the solid material. From Palik's data ${ }^{16}$ the absorption coefficient in silicon varies from $1 \mathrm{~cm}^{-1}$ to $2.3 \mathrm{~cm}^{-1}$ between 8.5 and $13 \mu \mathrm{m}$. This would result in $45 \%$ to $70 \%$ optical absorption loss in the grating.

The precision grinding techniques developed at RIKEN are optimized to produce large coarse echelles. The groove corner radii they have reported have been in the range of 15 to $30 \mu \mathrm{m}$. These values are larger than the period of the $\mathrm{DS} / 2$ grating and would have resulted in low efficiencies.

Some issues worthy of further study include the possible changes in grating surface figure after debonding from the machining fixture and also after coatings are applied. It would be useful to understand why our metallic coating had poorer immersed reflectivity (by nearly 10\%) than calculated. One could test other metallic coatings to see if they perform better than $\mathrm{Cr} / \mathrm{Au}$. Other directions for future work are indicated by two other papers that we are presenting at this conference. One discusses the issues involved in fabricating a large immersion grating beyond the size capability of the PERL ${ }^{17}$. Other machines at LLNL, either existing or under construction appear to have the necessary precision and stability for grating work. The other paper reviews the prospects for diamond machining other high index materials whose transmission extends down to the visible region ${ }^{18}$. This could enable the fabrication of immersion gratings at shorter wavelengths than are possible with germanium. 


\section{ACKNOWLEDGEMENTS}

I would like to thank a number of coworkers at LLNL for their contributions to the success of this project. Marcia Kellam measured the wavefront error of many of the gratings with a Zygo interferometer. This demonstrated that a diamond machining process could make high quality gratings. Jim Ferreira produced the SEM photos that helped diagnose the cutting problems and that also showed how good the gratings could be when the cutting process was optimized. Jackie Crawford and Tim Graff of the LLNL Microtechnologies Center did the initial cleaning and etching of the germanium blanks as well cleaning the finished gratings and sputtering the $\mathrm{Cr} / \mathrm{Au}$ reflective coating. This work was performed under the auspices of the U.S. Department of Energy by University of California, Lawrence Livermore National Laboratory under Contract W-7405-Eng-48.

\section{REFERENCES}

1. E. Hulthen and H. Neuhaus, "Diffraction Gratings in Immersion," Nature 173, pp. 442-443, 1954.

2. G. Wiedemann and D.E. Jennings, "Immersion grating for infrared astronomy," Applied Optics 32, pp. 1176-1178, 1993.

3. U.U. Graf, D. T. Jaffe, E. J. Kim, J. H. Lacy, H. Ling, J. T. Moore and G. Rebeiz, "Fabrication and evaluation of an etched infrared diffraction grating," Applied Optics 33 pp. 96-102, 1994.

4. P. J. Kuzmenko, D. R. Ciarlo and C. G. Stevens, "Fabrication and testing of a silicon immersion grating for infrared spectroscopy," in Optical Spectroscopic Techniques and Instrumentation for Atmospheric and Space Research, J. Wang and P. B. Hays, editors, Proceedings of SPIE vol. 2266, pp. 566-577, 1994.

5. J. Ge, D. McDavitt, J. Bernecker, S. Miller, D. Ciarlo and P. Kuzmenko, "Development of Silicon Grisms and Immersion Gratings for High Resolution Infrared Spectroscopy," in Optical Spectroscopic Techniques and Instrumentation for Atmospheric and Space Research IV, A. M. Larar and M. G. Mlynczak, Editors, Proceedings of SPIE vol. 4485, pp.393-404, 2001.

5. J. Stiens, W. Ranson, R. Cottam, C. De Tandt, R. Vounckx, V. Kotov, G. Shkerdin, B. Dhoedt and R. Baets, "Experimental characterizationof reactive ion etched germanium diffraction gratings at $10.6 \mu \mathrm{m} . "$ Applied Physics Letters 69, pp.3453-3455, 1996.

6. N. Ebizuka, M. Iye and T. Sasaki , "Optically anisotropic crystalline grisms and astronomical spectrographs," Applied Optics 37, pp.1236-1242, 1998..

7. H. Ohmori, N. Ebizuka, S. Morita and Y. Yamagata, "Ultraprecision Micro-Grinding of Germanium Immersion Grating Element for Mid-Infrared Super Dispersion Spectrograph," Annals of the CIRP 50, pp. 221-222, 2001.

8. H.U. Käufl, K. Kühl and S. Vogel, "Grisms from Germanium/Silicon for Astronomical Instruments," in Infrared Astronomical Instrumentation, Albert M. Fowler, Editor, Proceedings of SPIE Vol. 3354, pp.151-158, 1998.

9. N. Ebizuka, S. Morita, T. Shimizu, Y. Yamagata, H. Omori, M. Wakaki, H. Kobayashi, H. Tokoro and Y. Hirahara, "Development of immersion grating for mid-infrared high dispersion spectrograph for the $8.2 \mathrm{~m}$ Subaru telescope," in Specialized Optical Developments in Astronomy, E. Atad-Ettedgui and S. D'Odorico editors. Proceedings of SPIE Vol. 4842, pp.293-300, 2003.

10. S.A, Lerner, C.L. Bennett, J.V. Bixler, P.J. Kuzmenko and I.T. Lewis, "Compact Refractive Imaging Spectrometer Utilizing Immersed Gratings," US Patent \# 6922240, issued July 26, 2005.

11. P. J. Kuzmenko, L. M. Little, P. J. Davis and S. L. Little, "Modeling, Fabrication and Testing of a DiamondMachined Germanium Immersion Grating," in IR Space Telescopes and Instruments, J. Mather editor, Proceedings of SPIE Vol. 4850, pp.1179-90, 2002.

12. E. G. Loewen and E. Popov, Diffraction Gratings and Applications, p. 420, Dekker, New York, 1997.

13. Gsolver is a product of the Grating Solver Development Company, P.O. Box 353, Allen TX 75013. More information is available on their website at www.gsolver.com

14. M. P. Chrisp and S. A. Lerner, "Imaging Spectrometer Utilizing Immersed Gratings with Accessible Entrance Slit," US Patent \# 7016037, issued March 21, 2006.

15. E. D. Palik, Handbook of Optical Constants of Solids, Academic, Orlando, 1985.

16. P. J. Kuzmenko, P. J. Davis, S. L. Little, and L. C. Hale, "Design and fabrication issues for large immersion gratings," paper 6273-115, this conference.

17. P. J. Kuzmenko, "Prospects for machined immersion gratings in the near infrared and visible," paper 6273-146, this conference. 


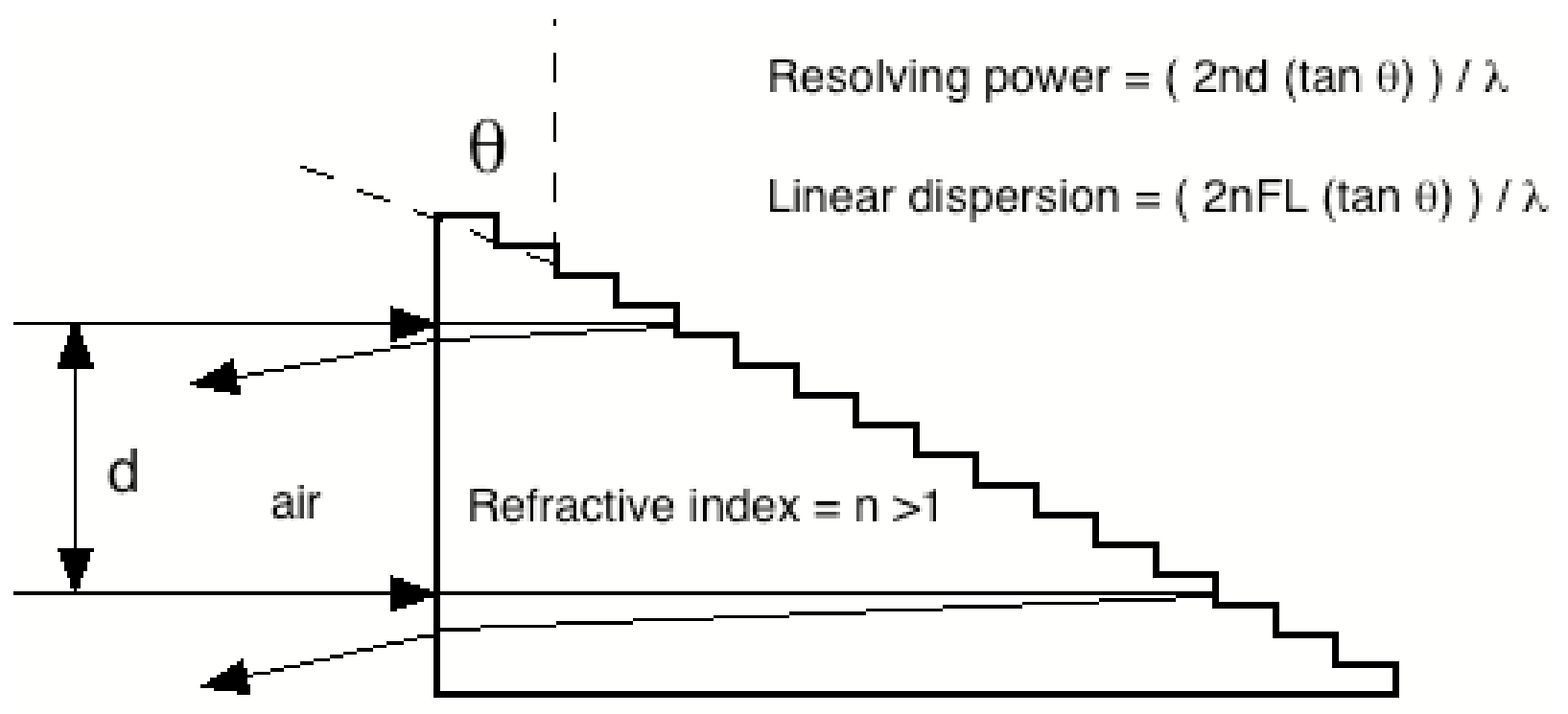

Figure 1 This diagram shows the optical path through an immersion grating. The dispersion and spectral resolution are increased by a factor $\mathrm{n}$, the refractive index of the transmissive material, relative to a reflective grating in air.

\section{U.S. Patent Jul. 26, 2005 Sheet 1 of $3 \quad$ US 6,922,240 B2}

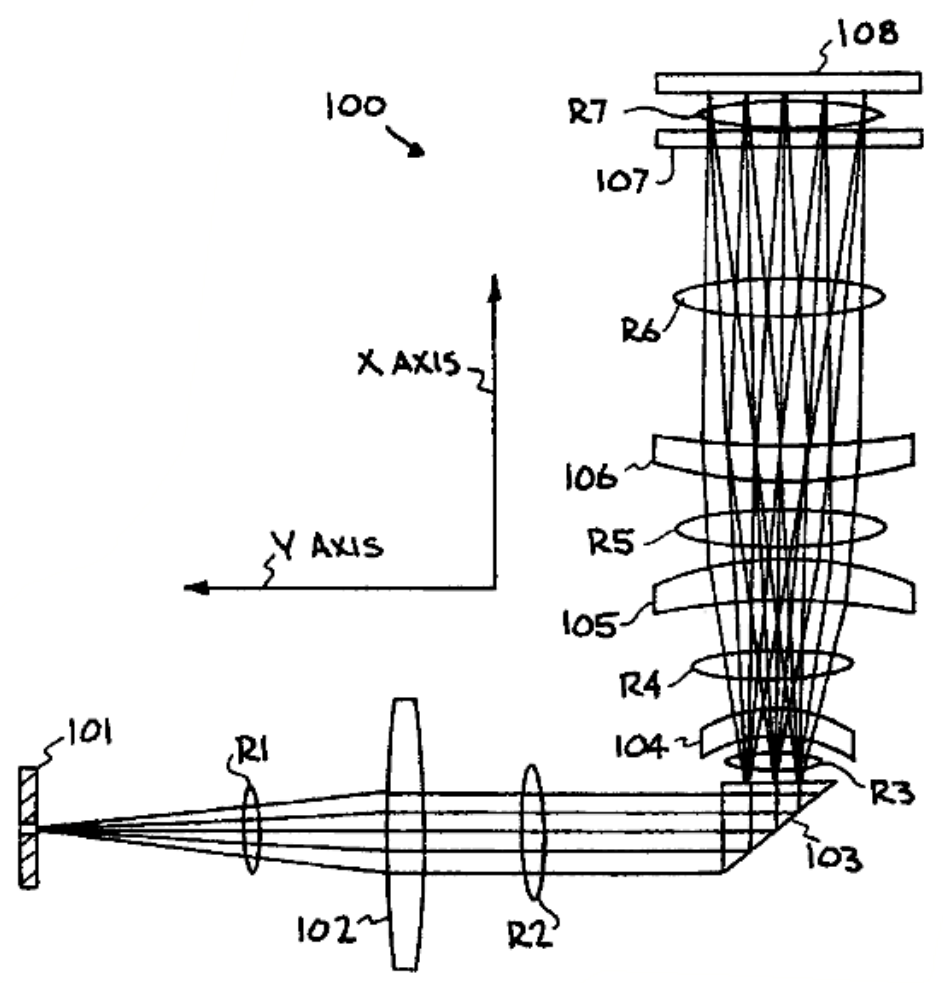

Figure 2. This is the optical layout of the DS/1 spectrometer. Light enters at the slit 101, is collimated by lens 102 onto the germanium immersion grating 103, is dispersed and then focused onto the focal plane at 108 . The grating grooves are on the hypotenuse of a right angle prism. 


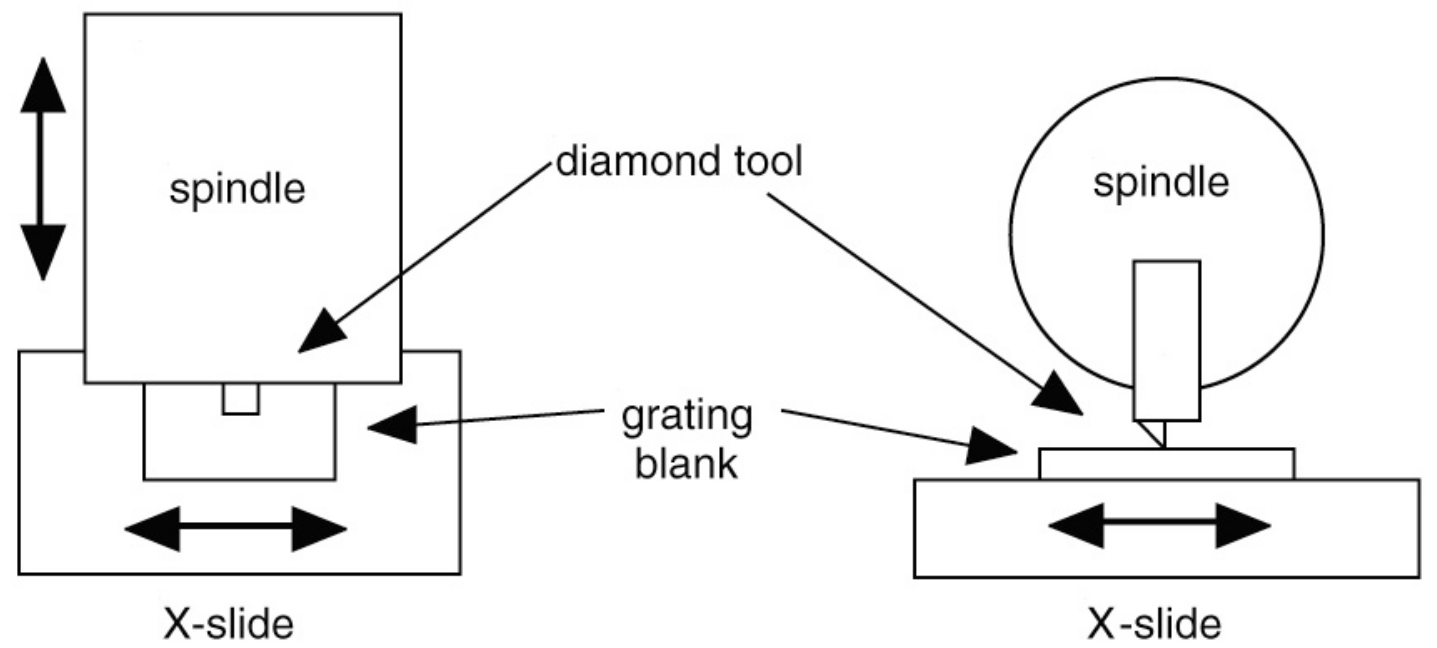

Figure 3 This is the machine configuration for diamond fly-cutting a grating. The X-slide slowly translates as the spindle rotates the tool, cutting a single groove. After completing a groove, the spindle retracts, the X-slide moves back to its starting position, and the spindle forward into position to cut the next groove.

\section{U.S. Patent Mar. 21, 2006 Sheet 1 of $6 \quad$ US 7,016,037 B2}

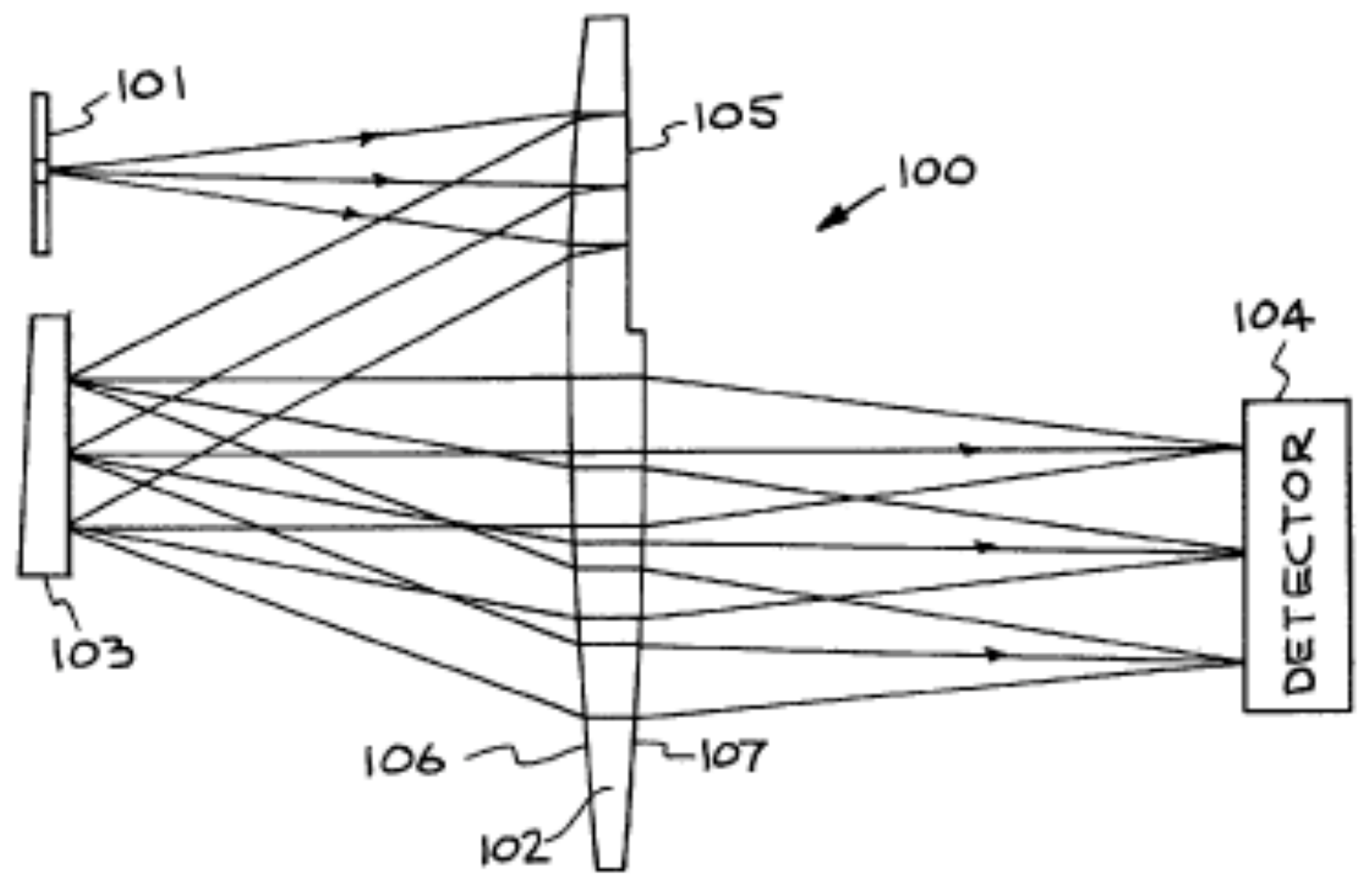

Figure 4. This is the optical layout of the DS/2 compact spectrometer. Light enters at the slit 101, is collimated onto the germanium immersion grating 103, dispersed and then focused onto the focal plane 104. The grating is machined on the back of a thin wedge. 


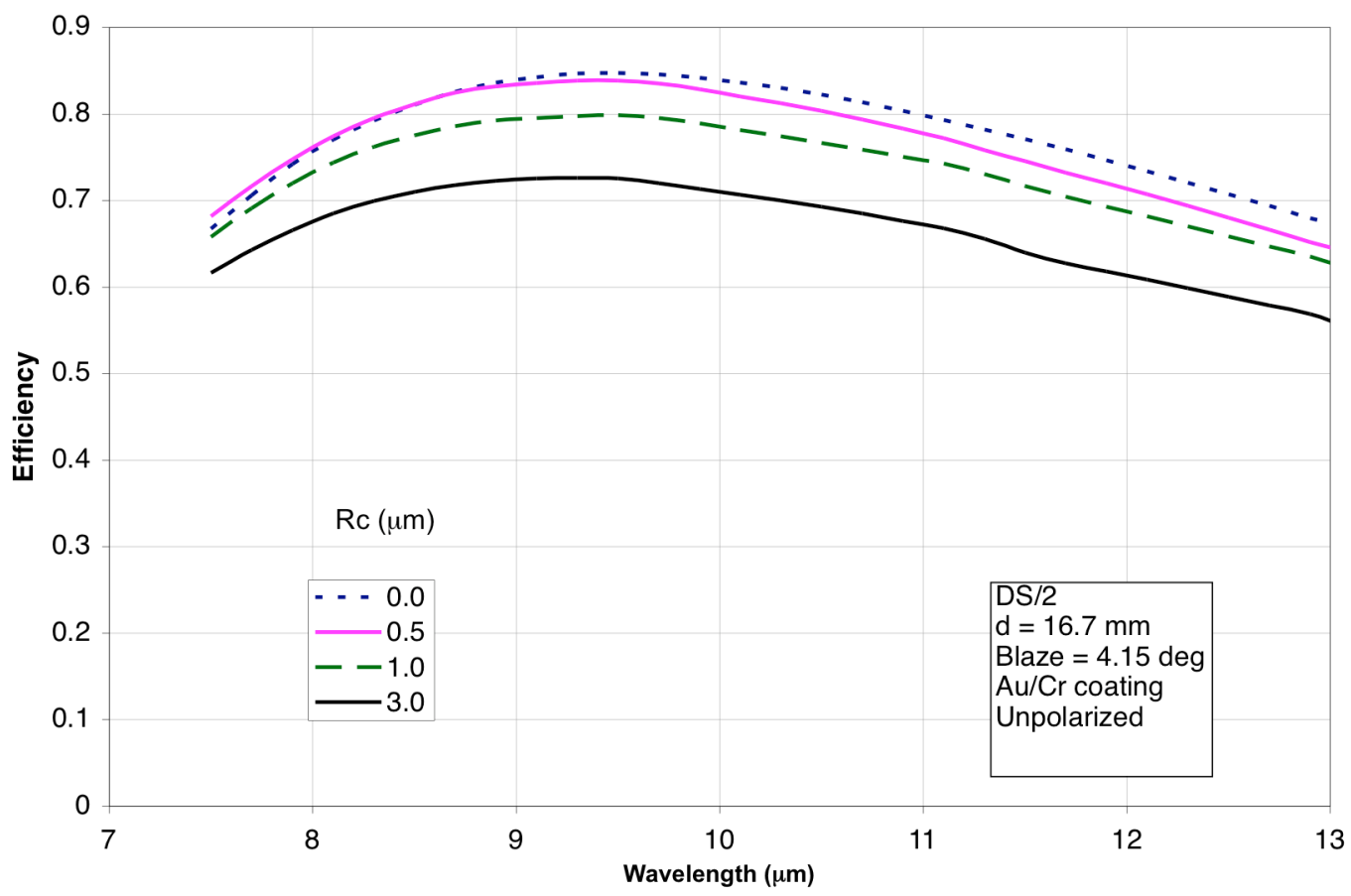

Figure 5. This plot shows the diffraction efficiency (calculated with GSolver) as a function of wavelength vs. groove corner radius for $\mathrm{DS} / 2$ grating. To get the highest efficiency grating, the groove corner radius must be less than $0.5 \mu \mathrm{m}$.

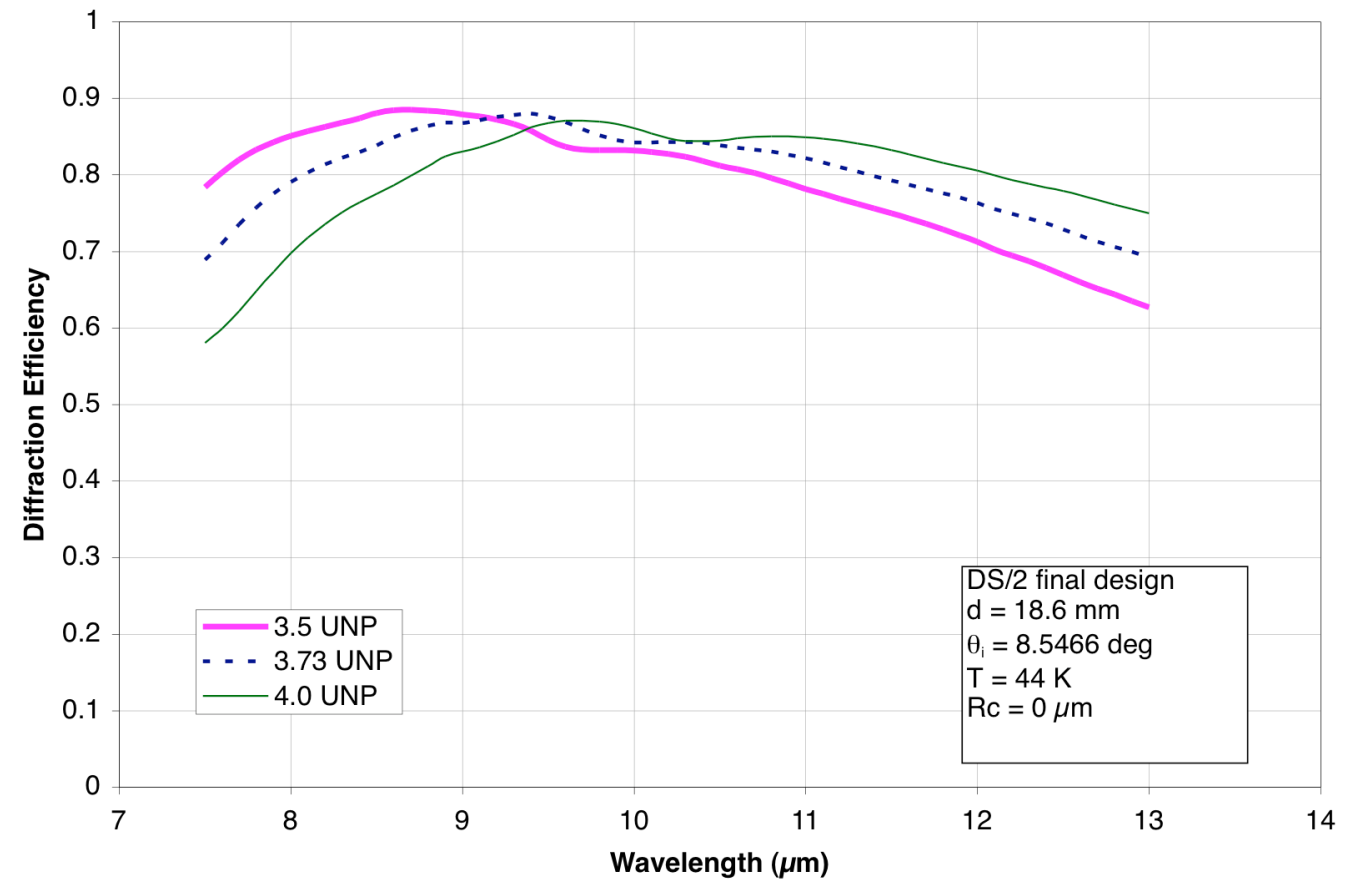

Figure 6. Final blaze optimization for DS/2 design with unpolarized light; first order diffraction efficiency vs. blaze angle 


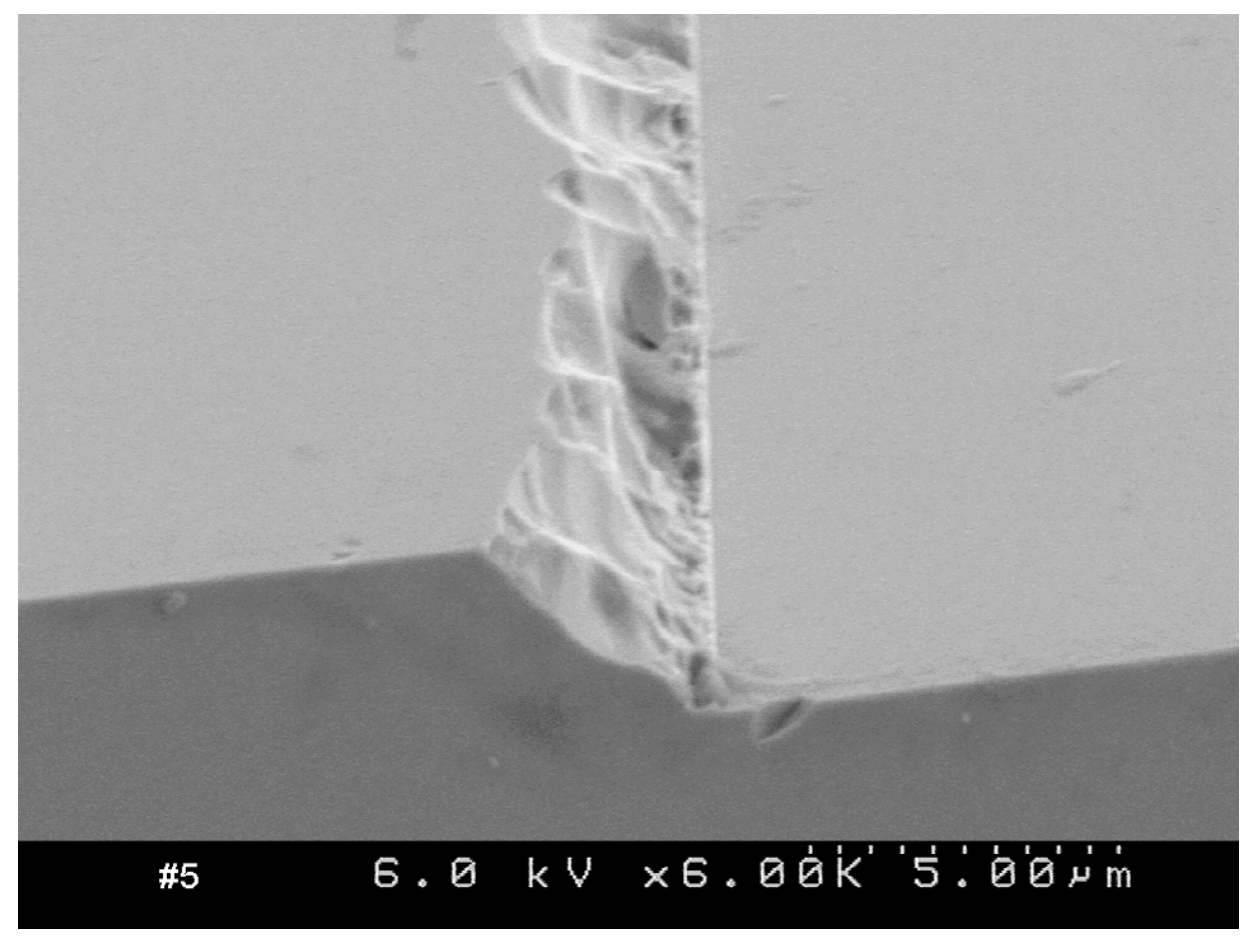

Figure 7.The first attempts to cut grooves with a dead sharp tool resulted in severe chipping of the vertical groove face.

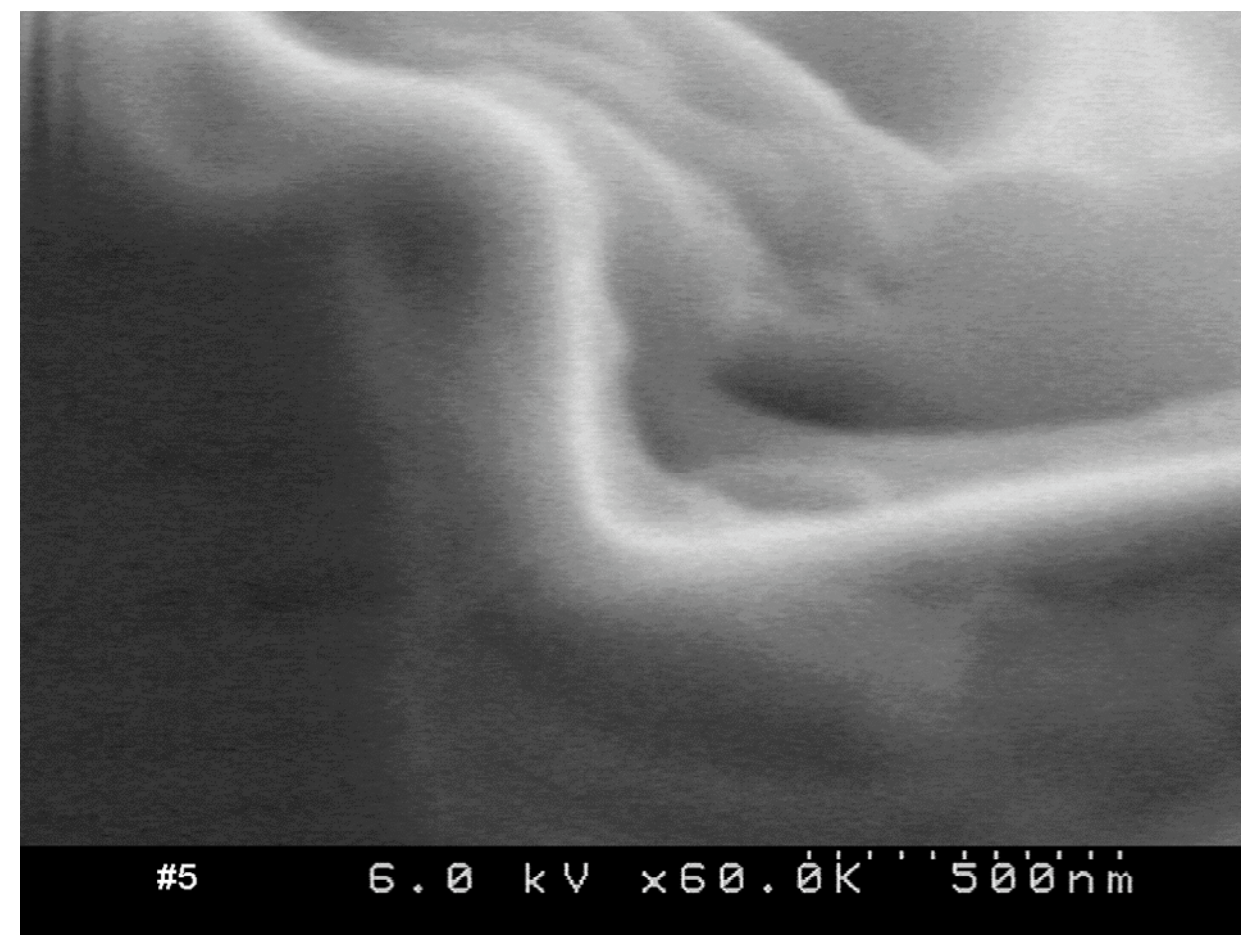

Figure 8. End on view of groove indicates a sharp groove radius below point at which vertical face is broken off. 


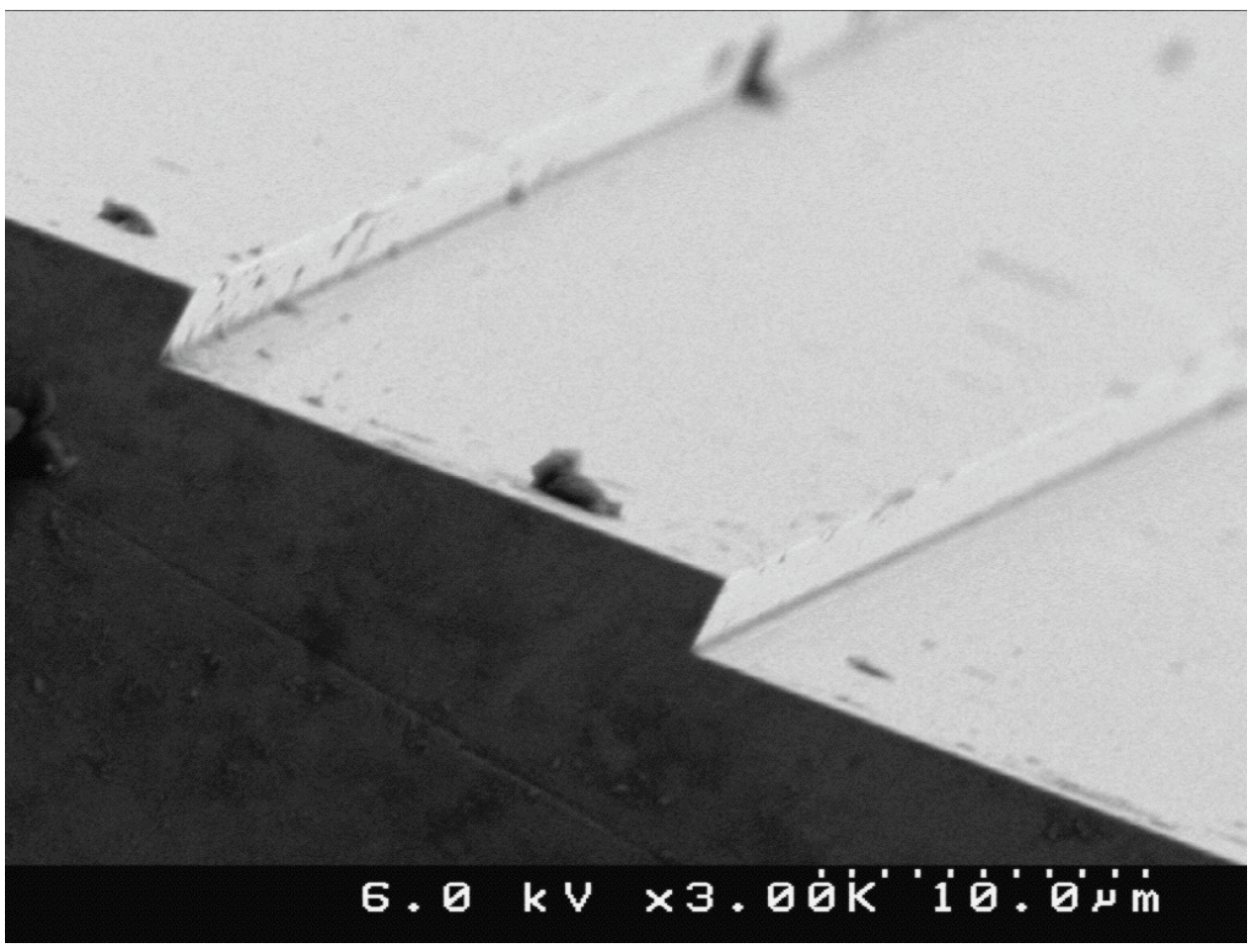

Figure 9. By dropping the feed rate to 0.1 inch/minute we were able to cut very sharp clean grooves with a "zero radius tool".

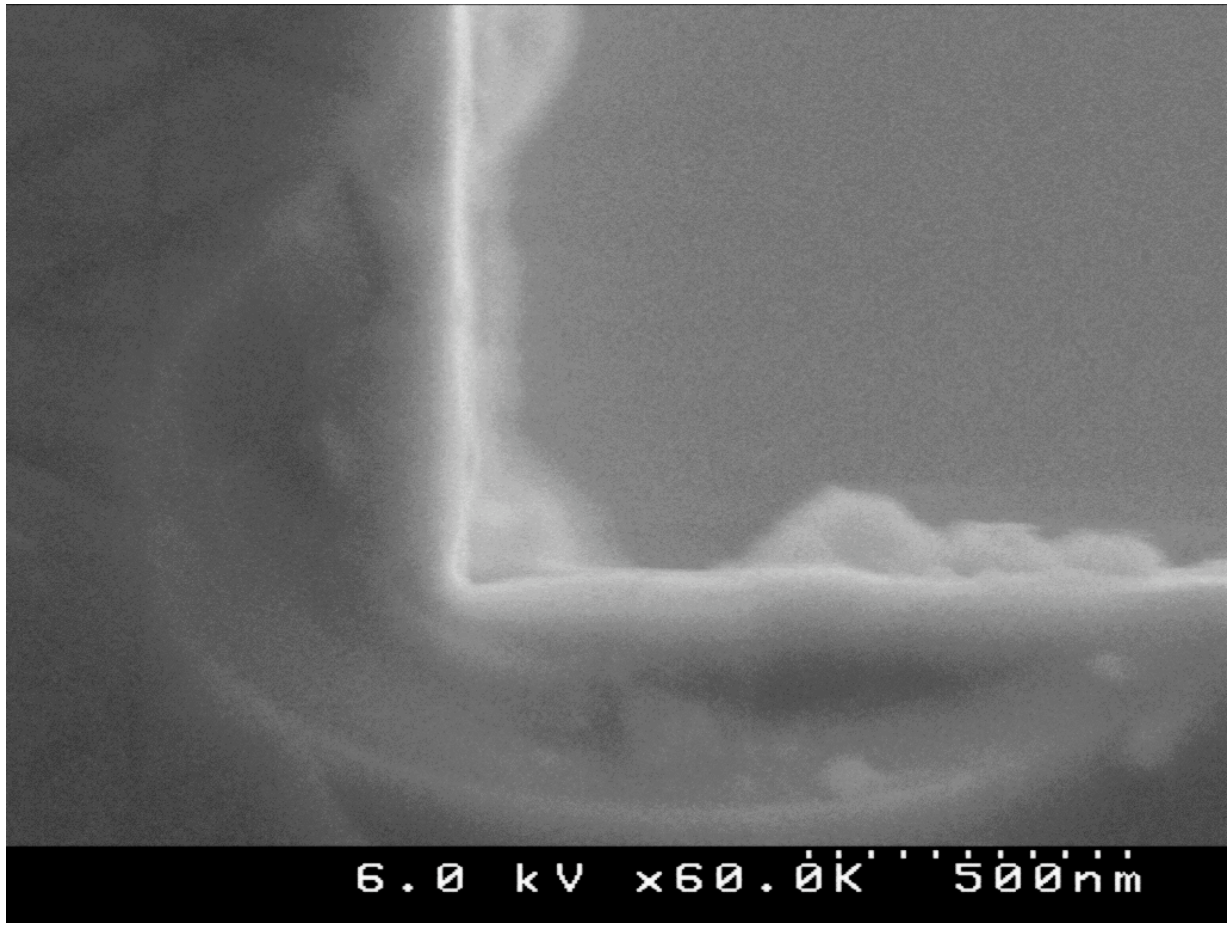

Figure 10. End on SEM photo of grating shows very sharp groove radius $<0.1 \mu \mathrm{m}$ cut into germanium 


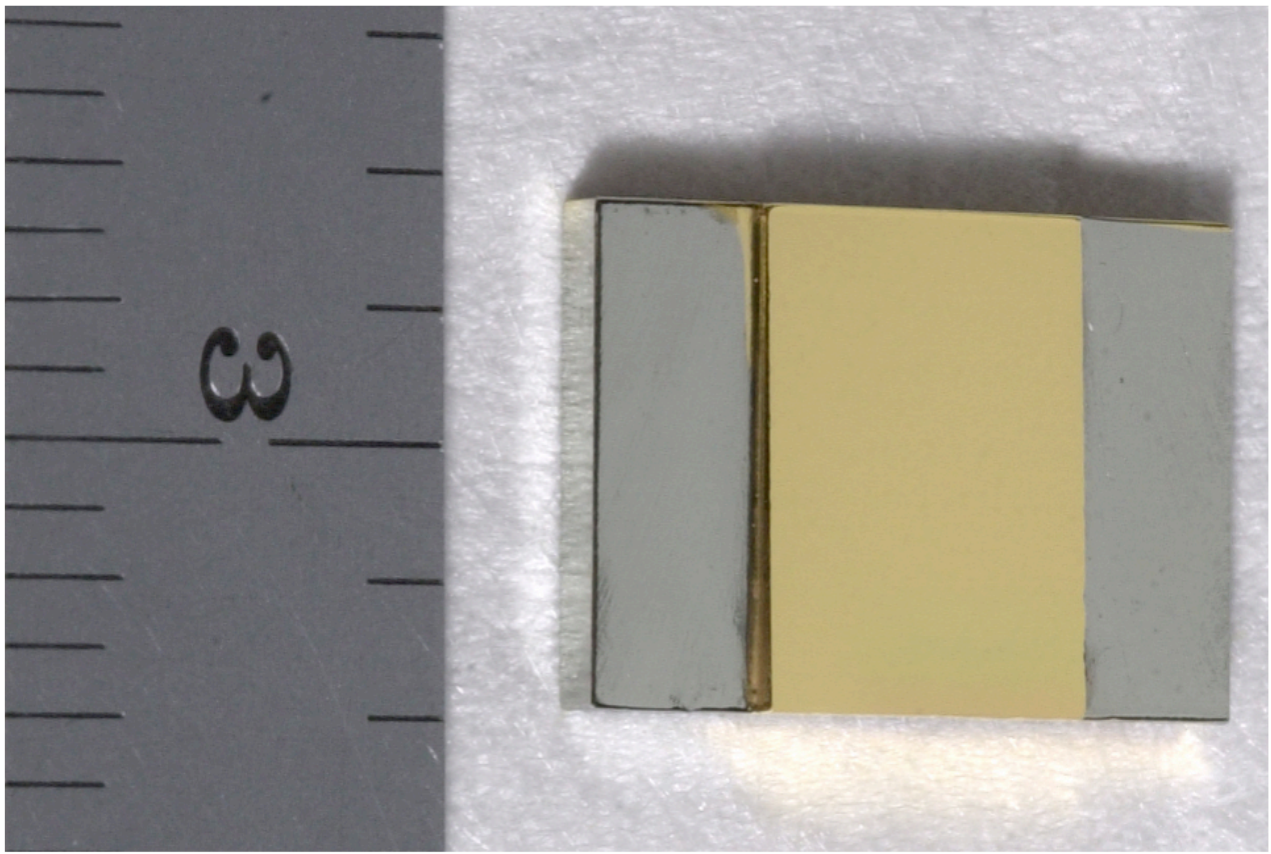

Figure 11. This is a photograph of a finished DS/2 immersion grating. The grooves are in the central section running parallel to the long side of the blank. The rightmost scale is $1 / 8$ inch per division; the left scale is $1 / 16$ inch per division.

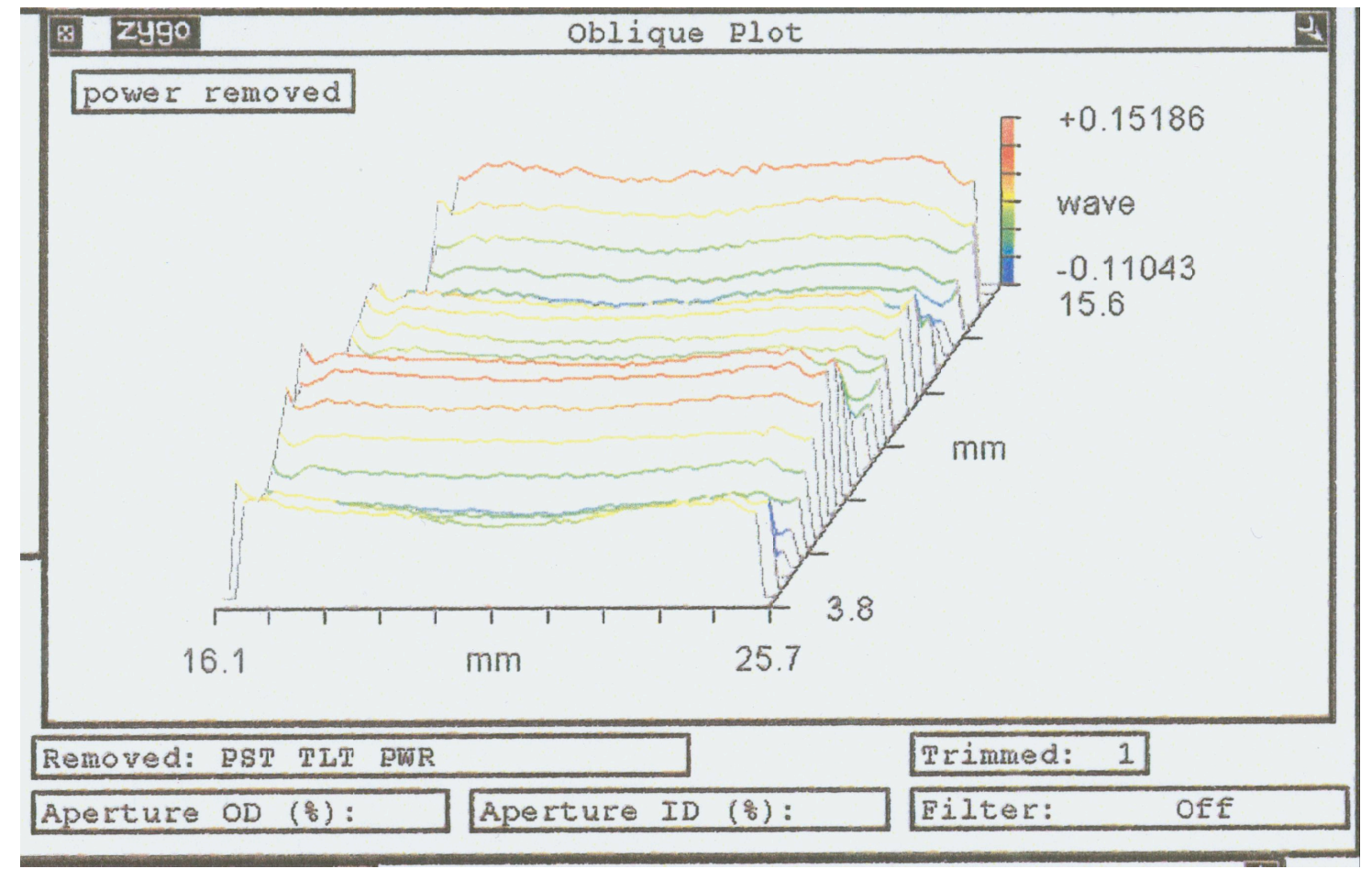

Figure 12. This is a 3D plot of the DS/2 grating \#4 wavefront taken with a $633 \mathrm{~nm}$ Zygo interferometer. Over the full grating surface the wavefront error (deviation from plane wave) is 0.262 wave peak to valley and 0.052 wave rms 


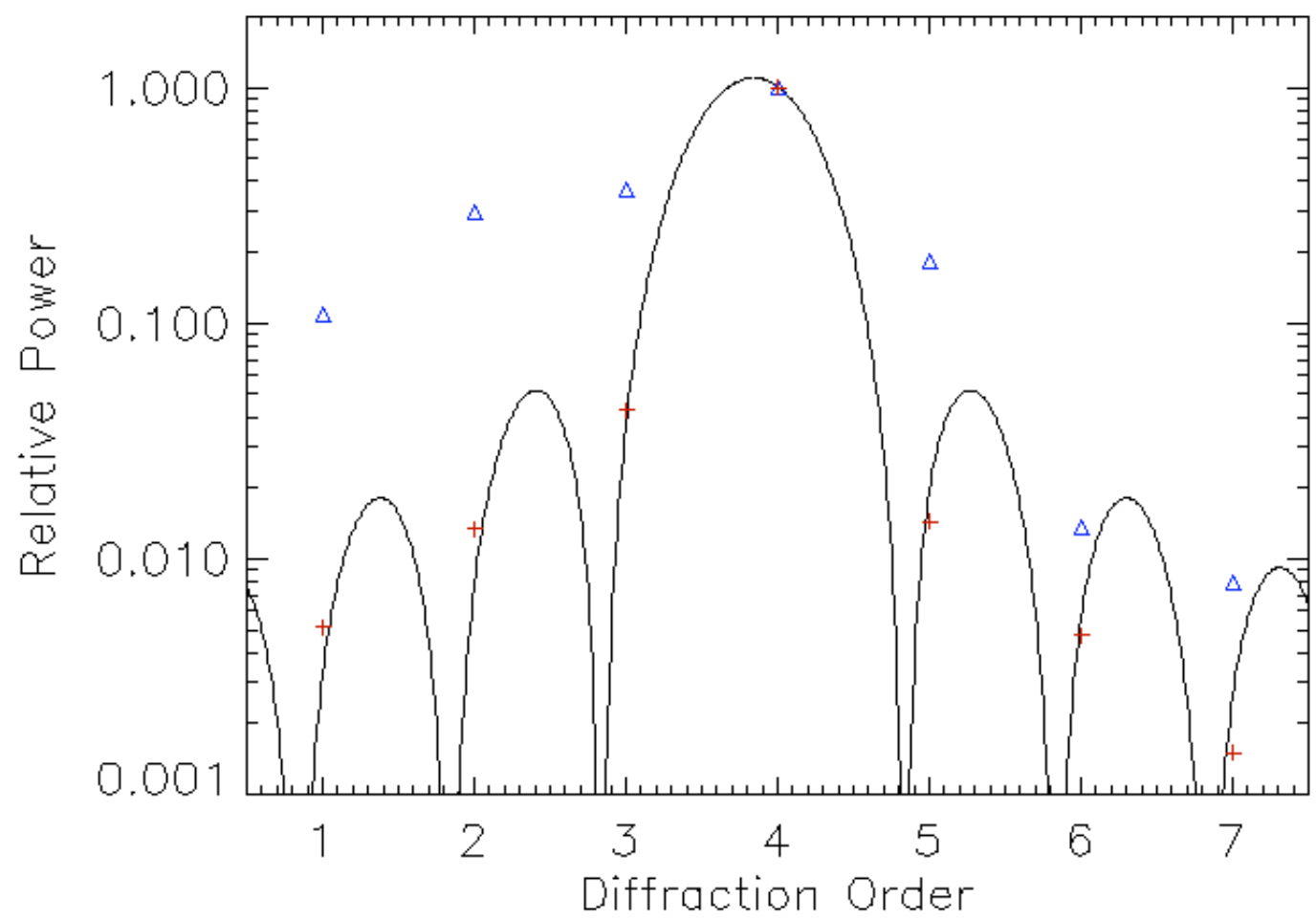

Figure 13. Relative power of diffracted orders from two DS2 gratings. The gratings were externally illuminated with a HeNe laser. The blue triangles are data points from grating \#2 which was cut with a $3 \mu \mathrm{m}$ radius tool. The red pluses are data points from \#3 which was cut with a dead sharp tool. The solid line fits the theoretical expectation.
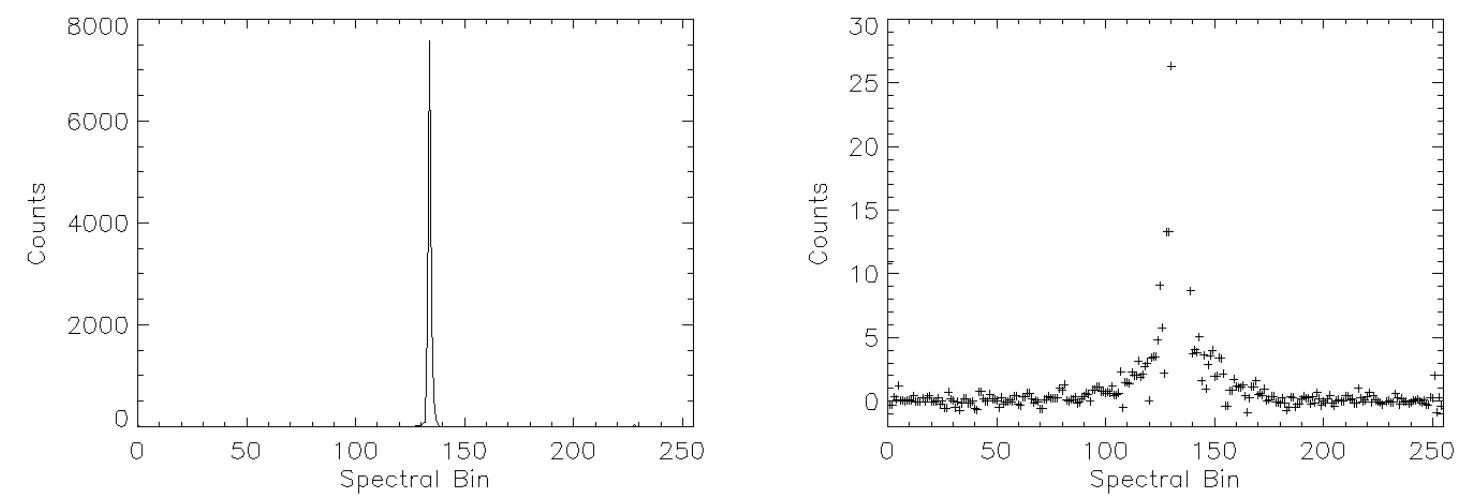

Figure 14. a.) Profile of $\mathrm{CO}_{2}$ laser line at $10.6 \mu \mathrm{m}$ b.) $\mathrm{CO}_{2}$ laser line plotted with an expanded scale. 